\title{
Analytical Calculation of Critical Anchoring Length of Steel Bar and GFRP Antifloating Anchors in Rock Foundation
}

\author{
Nan Yan, ${ }^{1,2}$ Xueying Liu, ${ }^{1}$ Mingyi Zhang, ${ }^{1,2}$ Xiaoyu Bai ${ }^{10},{ }^{1,2}$ Zheng Kuang, \\ Yongfeng Huang, ${ }^{1}$ Desheng Jing, ${ }^{1}$ Jun Yan, ${ }^{3,4}$ Cuicui Li, ${ }^{5}$ and Zhongsheng Wang ${ }^{3,4}$ \\ ${ }^{1}$ School of Civil Engineering, Qingdao University of Technology, Qingdao 266033, China \\ ${ }^{2}$ Cooperative Innovation Center of Engineering Construction and Safety, Shandong Blue Economic Zone, \\ Qingdao University of Technology, Qingdao 266033, China \\ ${ }^{3}$ Qingdao Geo-Engineering Survering Institute, Qingdao 266071, China \\ ${ }^{4}$ The Key Laboratory of Urban Geology and Underground Space Resources, \\ Shandong Provincial Bureau of Geology and Mineral Resources, Qingdao 266590, China \\ ${ }^{5}$ Qingdao Construction Group, Qingdao 266071, China
}

Correspondence should be addressed to Xiaoyu Bai; baixiaoyu538@163.com

Received 9 July 2020; Revised 23 December 2020; Accepted 31 December 2020; Published 12 January 2021

Academic Editor: Jose J. Muñoz

Copyright ( $\odot 2021$ Nan Yan et al. This is an open access article distributed under the Creative Commons Attribution License, which permits unrestricted use, distribution, and reproduction in any medium, provided the original work is properly cited.

\begin{abstract}
Antifloating anchors are widely used during the construction of slab foundations to prevent uplift. However, existing methods for calculating the critical length of these anchors have limited capabilities and therefore require further research. As the mechanisms which govern the displacement and stability of antifloating anchors are closely related to those of piles subject to uplift, a simplified anchor model has been developed based on existing concentric thin-walled cylinder shear transfer models used for pile design. Analytical expressions for the critical length of the steel bar and GFRP (glass fiber reinforced polymer) antifloating anchors in rock are derived accordingly before demonstrating the validity of the method through engineering examples. The research results show that when the length of an antifloating anchor is less than a critical length, shear slip failure occurs between the anchor and surrounding material due to excessive shear stress. When the length of an anchor approaches the critical length, the shear stress gradually decreases to the undisturbed state. If the anchor length is larger than the critical length, the uplift loads are safely transferred to the ground without causing failure. The ratio of elastic modulus between the anchor and rock mass was found to be positively correlated with the critical anchoring length. Because the elastic modulus of GFRP bars is lower than that of steel bars, the critical anchoring length of GFRP bars is greater than that of steel bars under the same anchor-to-rock modulus ratio $\left(E_{a} / E_{s}\right)$. The results show that the proposed calculation method for the critical length of antifloating anchors appears valid and could provide a theoretical basis for the design of antifloating anchors after further refinement.
\end{abstract}

\section{Introduction}

Antifloating anchors are widely used to prevent the uplift of slab foundations as they cause only small stress concentrations, employ simple construction technology, and are low cost [1-3]. Traditional steel bar antifloating anchors have proven effective under a range of conditions but have short design lives in harsh environments with corrosive ground water or electric currents produced by rail infrastructure. Nonmetallic antifloating anchors have the potential to overcome this limitation. Within this class of anchor, the glass fiber reinforced polymer (GFRP) type has become prominent due to the advantages of high tensile strength, corrosion resistance, electromagnetic interference resistance, and low cost [4-7].

In recent years, many scholars at home and abroad have conducted studies on the performance of anchors. Zhang et al. [8] proposed a time-varying model to describe the loaddeformation characteristics of GFRP soil nails during the pullout process by observing the continuous interaction 
between GFRP soil nails and sand. The tests were carried out to validate a proposed analytical model. Additionally, Trejo et al. [9] studied GFRP bars embedded in concrete under unsubmerged conditions for 7 years. In order to better assess the capacity loss and ACI design reduction factors, a probabilistic model of the time-varying bearing capacity of GFRP bars embedded in concrete is needed. In order to improve the anchoring performance of antifloating anchor, the anchoring length of anchor is usually increased. However, Bai et al. [10] found that there is a critical anchoring length in the steel bar and GFRP antifloating anchor through field drawing test, that is, the anchor will no longer be stressed after reaching a certain depth. This indicates that increasing the anchoring length without limit cannot continuously improve the anchoring performance of the antifloating anchor and will result in the consequence of increasing cost and material waste. Therefore, it is of great significance to determine the accurate calculation method of critical anchoring length of antifloating anchor with steel and GFRP bars for saving cost and improving construction efficiency.

At present, there are few reports on the calculation method of critical anchoring length of steel and GFRP anchors in rock foundation. In this paper, by combining the ideal concentric thin-walled cylinder shear model and the simplified shear stress distribution model of the antifloating anchor, the critical anchoring length of the steel bar and GFRP antifloating anchor is derived. Compared with an engineering example, the feasibility of the above calculation method is verified, and the influence of the ratio of elastic modulus of anchor to rock mass on the critical anchoring length is discussed.

\section{Basic Theory}

2.1. Calculation of Geotechnical Movement. Considering that the working mechanism of antifloating anchor is similar to that of uplift pile, the theory of uplift pile is used to analyze the antifloating anchor. Assuming that the rock and soil body around the anchor is an ideal elastic body and the anchoring solid in contact with the anchor body has the same properties as the surrounding rock and soil, without considering the increase of vertical stress, the soil deformation under the action of drawing load can be represented by the ideal concentric thin-walled cylindrical shear model (Figure 1) [11, 12]. The anchor interacts with the surrounding rock and soil to transfer the drawing load to the adjacent concentric cylinders, and this process is transmitted to $n$ cylinders. Using the method of unit selection for axisymmetric problems in space in the theory of elasticity, two cylinders separated by $\mathrm{d} r$, two vertical planes forming $\mathrm{d} \theta$, and two horizontal planes bounded by a tiny hexahedron separated by $\mathrm{d} z$ are selected as the units. Because the concentric cylinder model is an axisymmetric problem, there are only normal stress and axial shear stress on the two cylinders of the element body. There are only normal and radial shear stresses on the two planes. There is only annular stress on the two vertical surfaces, and the increment is 0 . The force on the element body is shown in Figure 2.

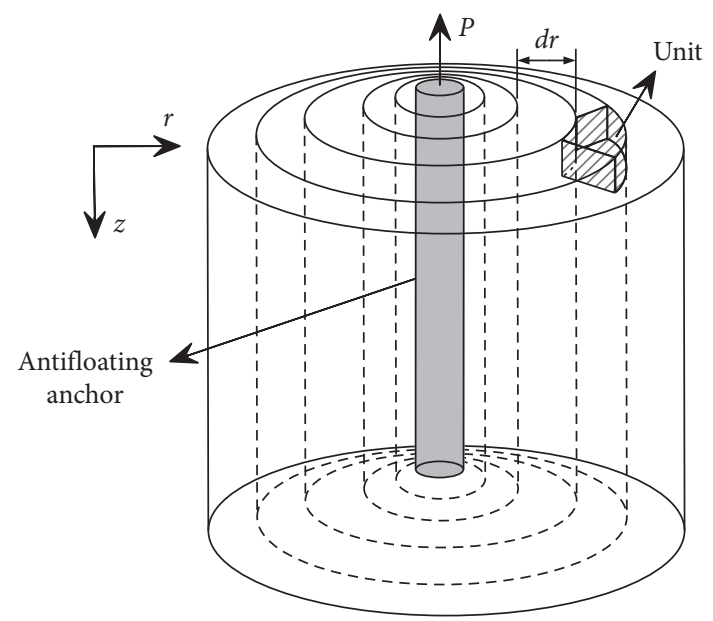

FIGURE 1: Concentric thin wall cylinder shear model.

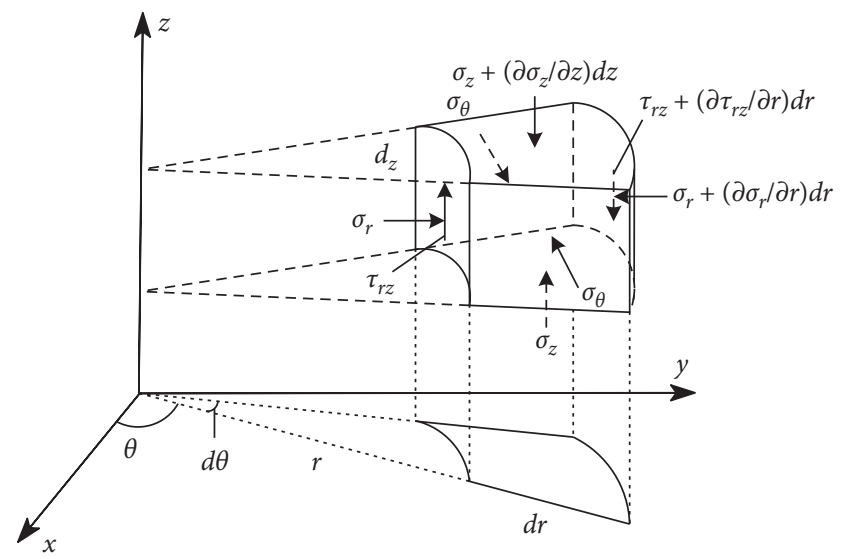

Figure 2: Schematic diagram of the unit force.

In Figures 1 and 2, $P$ represents the drawing load on the anchor; $\sigma_{r}, \sigma_{\theta}$, and $\sigma_{z}$ represent the normal stress along the $r$, $\theta$, and $z$ directions, respectively; $\tau_{r z}$ represents the shear stress acting on the cylinder along the $z$-axis; $r$ represents the distance between the element body and the $z$-axis; and $\theta$ represents the rotation angle of the element body from the $x$ axis.

As shown in Figure 1, the $z$-axis torque balance of the model can be obtained by combining with the force exerted on the element in Figure 2:

$$
\tau_{0} r_{0}=\tau_{r z} r
$$

where $\tau_{0}$ is the shear stress at the interface between the anchor and the surrounding rock and soil and $r_{O}$ is the anchor radius.

In combination with Figure 2, ignoring the physical force of the element, the balance equation of spatial axisymmetric problem of elastic mechanics can be obtained as follows:

$$
\frac{\partial \sigma_{z}}{\partial z}+\frac{\partial \tau_{r z}}{\partial r}-\frac{\tau_{r z}}{r}=0
$$


When the anchor is under tension, the shear stress variation of the element in the rock and soil is much greater than that of the vertical normal stress. Therefore, $\partial \sigma_{z} / \partial z=0$ is considered, which is ignored. Therefore, equation (2) becomes

$$
\frac{\partial \tau_{r z} \cdot r}{\partial r}=\tau_{r z}
$$

Integrate both sides of equation (3) and combine with equation (1) to obtain

$$
\tau_{r z}=\frac{\tau_{0} r_{0}}{r} .
$$

Assuming that the displacement of the unit in Figure 2 along the $z$-axis direction is $\omega$, the displacement along the $r$-axis direction is $\mu$, and the hoop displacement is 0 , then its shear displacement can be expressed as

$$
\gamma_{r z}=\frac{\tau_{r z}}{G_{s}}=\frac{\partial \mu}{\partial z}+\frac{\partial \omega}{\partial r},
$$

where $\gamma_{r z}$ is the shear displacement of unit and $G_{s}$ stands for shear modulus of rock and soil mass.

The unit mainly has vertical displacement. Therefore, ignoring its displacement along the direction of $r$-axis, equation (5) becomes

$$
\frac{\tau_{r z}}{G_{s}}=\frac{\partial \omega}{\partial r} .
$$

For uniform soil mass, combined with equations (6) and (4), the following equation can be obtained:

$$
\frac{\tau_{0} r_{0}}{r G_{s}}=\frac{\partial \omega}{\partial r} .
$$

Integrating equation (7), the result is

$$
\omega_{s}=\frac{\tau_{0} r_{0}}{G_{s}} \int_{r_{0}}^{r_{m}} \frac{1}{r} \mathrm{~d} r
$$

where $\omega_{s}$ is the total displacement of rock and soil mass and $r_{m}$ is the effective influence radius of the drawing load, beyond which the influence of the drawing load on the surrounding rock and soil mass can be ignored.

Cooke et al. [13] found that the rock and soil mass hardly deforms when the anchor radius is more than 20 times, so

$$
r_{m}=20 r_{0},
$$

where $\mu_{s}$ is Poisson's ratio of rock and soil mass and $L_{c}$ is the critical anchoring length of anchor.

By calculating equation (8), the total displacement of the rock and soil mass can be expressed as

$$
\omega_{s}=\frac{\tau_{0} r_{0}}{G_{s}} \cdot \ln \left(\frac{r_{m}}{r_{0}}\right) .
$$

2.2. Displacement Calculation of Steel Antifloating Anchor. A large number of test results showed that [14], under the action of drawing load, the shear stress between the steel bar antifloating anchor and the anchoring solid reaches its maximum value at a shallow distance from the orifice, then gradually develops downward, and finally attenuates to 0 at a certain depth.

To simplify the calculation, the shear stress distribution of the steel bar antifloating anchor is regarded as an inverse right triangle distribution, that is, it reaches a peak value on the upper surface of the rock and soil mass, then decreases linearly downward, and drops to 0 at the critical anchoring length, as shown in Figure 3. In Figure 3, $P$ is the pulling load, $L_{c}$ is the critical anchoring length of anchor, and $\tau_{1}$ is the shear stress at the entrance, namely the peak shear stress.

In order to master the anchoring performance between the anchor body and the anchoring solid as a whole, Won et al. [15] proposed a method to solve the average shear stress of the anchor. The distribution mode is shown as dotted line in Figure 3, which is expressed by equation (11):

$$
\bar{\tau}=\frac{P}{2 \pi r_{0} L_{c}},
$$

where $\bar{\tau}$ is the average shear stress of the anchor and $r_{0}$ is the anchor radius.

In order to ensure that the total shear stress obtained under the inverted triangle model is equal to the average shear stress model, there are the following relationships:

$$
\tau_{1}=2 \bar{\tau} .
$$

Thus, the shear stress distribution function of the anchor under the inverted triangle model is

$$
\tau(x)=\tau_{1} \cdot\left(1-\frac{x}{L_{c}}\right)=\frac{P}{\pi r_{0} L_{c}} \cdot\left(1-\frac{x}{L_{c}}\right)\left(0 \leq x \leq L_{c}\right),
$$

where $\tau(x)$ is the shear stress of the solid interface between anchor body and anchoring solid when the depth is $x$.

The anchoring solid is regarded as an elastic body, and the distribution function of its axial force along the anchorage depth is

$$
\begin{aligned}
P(x) & =2 \pi r_{0} \cdot \int_{x}^{L_{c}} \frac{P}{\pi r_{0} L_{c}} \cdot\left(1-\frac{t}{L_{c}}\right) \mathrm{d} t, \\
& =P\left(1-\frac{2 x}{L_{c}}+\frac{x^{2}}{L_{c}^{2}}\right) .
\end{aligned}
$$

According to Hooke's law, the elastic displacement of the bar top can be expressed as

$$
\omega_{s a}=\int_{0}^{L_{c}} \frac{P(x)}{\pi r_{0}^{2} E_{s a}} \mathrm{~d} x=\frac{P L_{c}}{3 \pi r_{0}^{2} E_{s a}},
$$

where $E_{s a}$ is the elastic modulus of the steel bar anchor.

2.3. Displacement Calculation of GFRP Antifloating Anchor. The elastic modulus of GFRP bars is much lower than that of steel bars, and the behavior of shear stress under pull-out load is different from that of steel bars. The results of relevant tests [16-19] show that, compared with the steel antifloating 


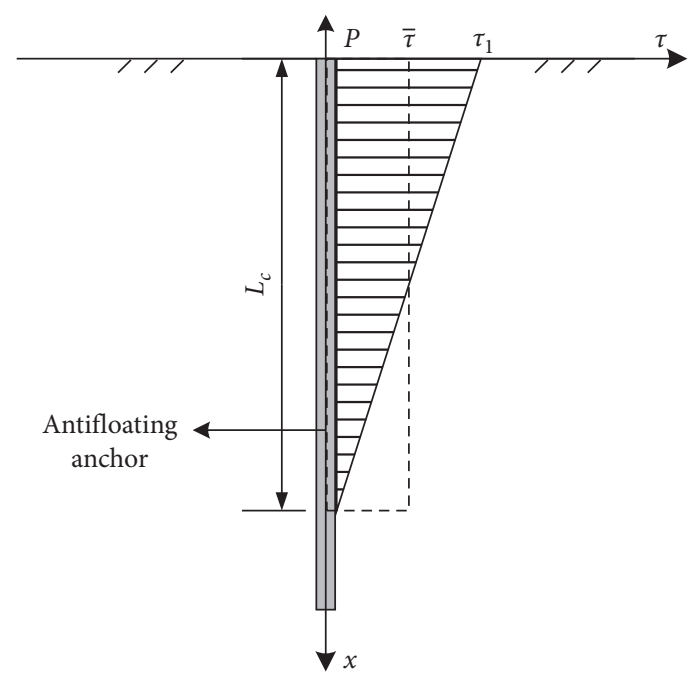

Figure 3: Simplified model for the shear stress of steel antifloating anchor.

anchor, the peak shear stress of the GFRP antifloating anchor appears in a deeper place, and the distribution law is quite different from that of the inverted triangle model. Therefore, it is necessary to improve the calculation method of anchor displacement to make it more suitable for GFRP antifloating anchor.

As shown in Figure 4, the peak shear stress of the GFRP antifloating anchor is located at position $L_{x}$ away from the ground, and the peak value is still $\tau_{1}$. The shear stress distribution is bounded by the peak point and gradually decreases upward and decreases to 0 at the orifice. The downward shear stress of the peak point also decreases gradually and drops to 0 at the position of the critical anchoring length $L_{c}$.

In order to ensure that the total shear stress is constant, $\tau_{1}$ in the GFRP shear stress model still satisfies the relationship of equations (11) and (12).

From Figure 4, the expression of GFRP antifloating anchor shear stress distribution is

$$
\tau(x)=\left\{\begin{array}{l}
\frac{P}{\pi r_{0} L_{c} L_{x}} \cdot x\left(0 \leq x<L_{x}\right), \\
\frac{P}{\pi r_{0} L_{c}} \cdot\left(\frac{L_{c}-x}{L_{c}-L_{x}}\right)\left(L_{x} \leq x \leq L_{c}\right) .
\end{array}\right.
$$

Its axial force distribution is

$$
\begin{aligned}
P(x) & =2 \pi r_{0} \int_{x}^{L_{c}} \tau(t) \mathrm{d} t, \\
& =\left\{\begin{array}{l}
\frac{P}{L_{c}}\left(L_{c}-\frac{x^{2}}{L_{x}}\right)\left(0 \leq x<L_{x}\right), \\
\frac{P\left(L_{c}-x\right)^{2}}{L_{c}\left(L_{c}-L_{x}\right)}\left(L_{x} \leq x \leq L_{c}\right) .
\end{array}\right.
\end{aligned}
$$

According to Hooke's law, the elastic displacement of the rod top is

$$
\begin{aligned}
\omega_{G a} & =\int_{0}^{L_{c}} \frac{P(x)}{\pi r_{0}^{2} E_{G a}} \mathrm{~d} x, \\
& =\frac{P}{3 \pi r_{0}^{2} E_{G a}}\left(L_{c}-5 L_{x}+\frac{2 L_{x}^{2}}{L_{c}}\right) .
\end{aligned}
$$

2.4. Calculation of Critical Anchoring Length of Antifloating Anchor. Assuming that the antifloating anchor deforms in harmony with the surrounding rock and soil, the displacement of the anchor top should be equal to the displacement of the surrounding rock and soil. The critical anchoring lengths of the steel bar and GFRP antifloating anchors are solved separately.

(1) For the steel bar antifloating anchor, with $\omega_{s}=\omega_{s a}$, substituting equations (10) and (15) into equation (18), it can be obtained as follows:

$$
\frac{P L_{c}}{3 \pi r_{0}^{2} E_{s a}}=\frac{\tau_{0} r_{0}}{G_{s}} \cdot \ln \left(\frac{r_{m}}{r_{0}}\right)
$$

For the elastic soil, it can be obtained as follows:

$$
G_{s}=\frac{E_{s}}{2\left(1+\mu_{s}\right)}
$$

where $E_{s}$ is the elastic modulus of rock and soil mass. Substituting equations (11), (12), (20), into (19) and simplifying,

$$
\frac{\tau_{1} L_{c}^{2}}{3 r_{0}^{2} E_{s a}}=\frac{2 \tau_{0}\left(1+\mu_{s}\right)}{E_{s}} \cdot \ln \left(\frac{r_{m}}{r_{0}}\right)
$$

It should be noted that $\tau_{1}$ on the left side of equation (21) represents the shear stress of the anchor at the orifice in the model shown in Figure 3. $\tau_{0}$ on the right side of the equation represents the shear stress of a unit of the innermost concentric cylinder (that is, the 


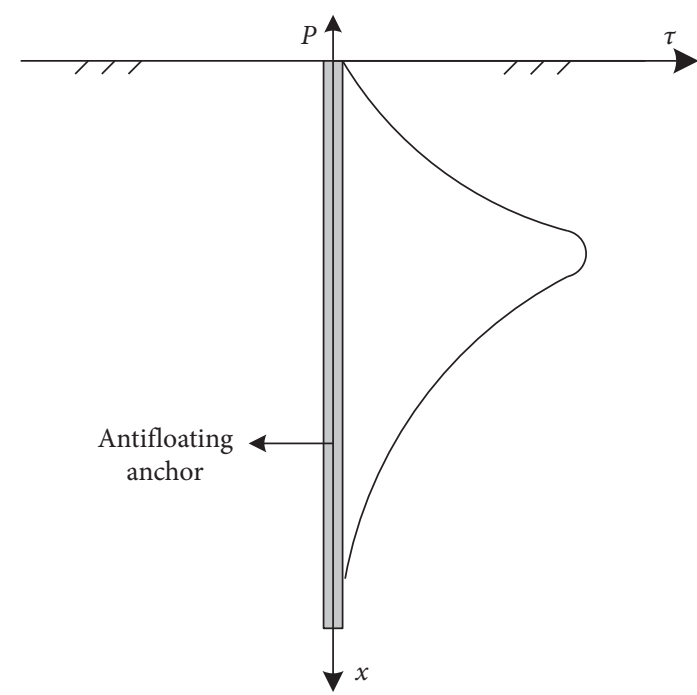

(a)

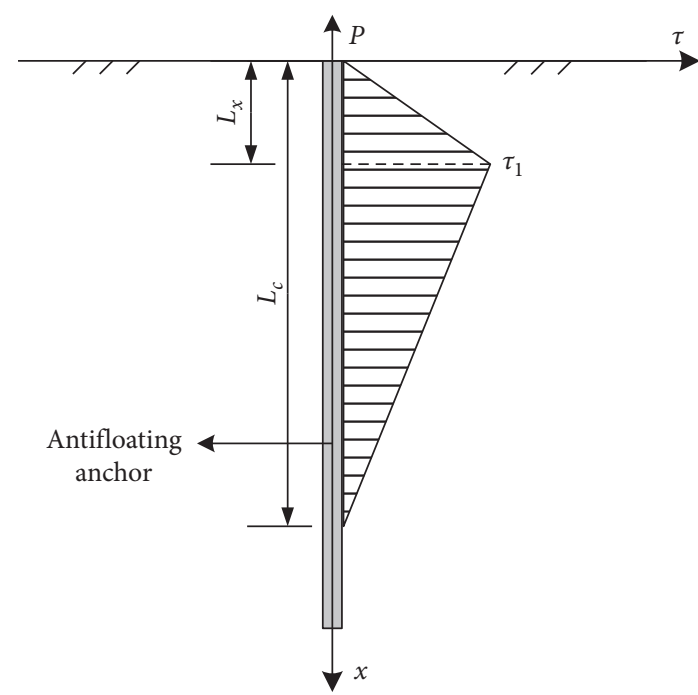

(b)

Figure 4: Simplified model for the shear stress of GFRP antifloating anchor. (a) Theoretical distribution diagram. (b) Simplified model of shear stress distribution.

anchor) in the model shown in Figure 1. The shear stress of a certain unit, for the unit near the orifice, $\tau_{0}$ has the same meaning as $\tau_{1}$ on the left side of the equation, which is the shear stress of the antifloating anchor at the orifice. Therefore, equation (21) can be simplified to

$$
\frac{L_{c}^{2}}{3 r_{0}^{2} E_{s a}}=\frac{2\left(1+\mu_{s}\right)}{E_{s}} \cdot \ln \left(\frac{r_{m}}{r_{0}}\right)
$$

According to equation (9), the expression of critical anchoring length of reinforced antifloating anchor is obtained after simplifying equation (22):

$$
L_{c}=r_{0} \sqrt{6 \cdot \ln 20 \cdot\left(1+\mu_{s}\right) \cdot \frac{E_{s a}}{E_{s}}} .
$$

(2) For GFRP antifloating anchor, $\omega_{s}=\omega_{G a}$, and substituting equations (10) and (18) into $\omega_{s}=\omega_{G a}$, it can be obtained as follows:

$$
\frac{\tau_{0} r_{0}}{G_{s}} \cdot \ln \left(\frac{r_{m}}{r_{0}}\right)=\frac{P}{3 \pi r_{0}^{2} E_{G a}}\left(L_{c}-5 L_{x}+\frac{2 L_{x}^{2}}{L_{c}}\right) .
$$

Using the same simplification method as the steel bar antifloating anchor and substituting equations (11), (12), and (20) into (24), it can be obtained as follows:

$$
\left(L_{c}-\frac{5}{2} L_{x}\right)^{2}=\ln \left(\frac{r_{m}}{r_{0}}\right) \cdot \frac{6 r_{0}^{2}\left(1+\mu_{s}\right) E_{G a}}{E_{s}}+\frac{17}{4} L_{x}^{2} .
$$

The critical anchoring length of GFRP antifloating anchor is obtained as

$$
L_{c}=\frac{5}{2} L_{x}+\sqrt{6 \cdot \ln 20 \cdot\left(1+\mu_{s}\right) r_{0}^{2} \cdot \frac{E_{G a}}{E_{s}}+\frac{17}{4} L_{x}^{2}} .
$$

In addition, since the simplified model of shear stress distribution cannot determine the location of $L_{x}$, this paper uses the following method to solve it.

You [20] used the Mindlin displacement solution to find the shear stress distribution of the antifloating anchor:

$$
\tau(x)=\frac{P}{\pi r_{0}} \cdot\left(\frac{t x}{2}\right) \cdot e^{\left(-t x^{2} / 2\right)},
$$

where $t=1 /\left(1+\mu_{s}\right)\left(3-2 \mu_{s}\right) r_{0}^{2} \cdot E_{s} / E_{G a}$.

Since the shear stress distribution of the GFRP antifloating anchor has only one peak point, the point where the derivative function of equation (27) is 0 can be used to determine the location of $L_{x}$, and the final result is

$$
\begin{aligned}
{\left[\frac{P}{\pi r_{0}} \cdot\left(\frac{t x}{2}\right) \cdot e^{-\left(t x^{2} / 2\right)}\right]^{\prime} } & =0, \\
\Rightarrow x & =\sqrt{\frac{1}{t}} .
\end{aligned}
$$

The critical anchoring length of GFRP antifloating anchor rod is obtained by substituting equations (28) into (26):

$$
L_{c}=\frac{5}{2} \sqrt{\frac{1}{t}}+\sqrt{6 \cdot \ln 20 \cdot\left(1+\mu_{s}\right) r_{0}^{2} \cdot \frac{E_{G a}}{E_{s}}+\frac{17}{4 t}},
$$

where $t=1 /\left(1+\mu_{s}\right)\left(3-2 \mu_{s}\right) r_{0}^{2} \cdot E_{s} / E_{G a}$.

\section{Example Analysis}

In this section, the above theoretical method will be used to calculate the critical anchoring length of the antifloating anchor in different tests and compare it with the actual 
TABLE 1: Calculating parameters and anchoring length of steel anchors.

\begin{tabular}{lcccccc}
\hline Anchor test source & $r_{0}(\mathrm{~mm})$ & $\mu_{s}$ & $E_{s a}(\mathrm{GPa})$ & $E_{s}(\mathrm{MPa})$ & Test anchoring length $(\mathrm{m})$ & Theoretical critical anchoring length $(\mathrm{m})$ \\
\hline$[21]$ & 8 & 0.3 & 200 & $3 \times 10^{4}$ & 0.15 & 0.100 \\
{$[22]$} & 15 & 0.5 & 200 & $5.43 \times 10^{4}$ & 0.8 & 0.149 \\
{$[23]$} & 14 & 0.33 & 200 & 30 & 3 & 5.589 \\
\hline
\end{tabular}

TABLE 2: Calculating parameters and anchoring length of GFRP anchors.

\begin{tabular}{lcccccc}
\hline Anchor test source & $r_{0}(\mathrm{~mm})$ & $\mu_{s}$ & $E_{s a}(\mathrm{GPa})$ & $E_{s}(\mathrm{MPa})$ & Test anchoring length $(\mathrm{m})$ & Theoretical critical anchoring length $(\mathrm{m})$ \\
\hline$[17]$ & 14 & 0.33 & 51 & 32 & 5 & 5.871 \\
{$[18]$} & 14 & 0.33 & 45 & 32 & 6.45 & 5.514 \\
{$[23]$} & 14 & 0.33 & 51 & 30 & 3 & 6.063 \\
{$[24]$} & 16 & 0.25 & 43 & $3.05 \times 10^{3}$ & 0.65 & 0.624 \\
\hline
\end{tabular}

anchoring length. At the same time, the rationality of the design of the anchoring length will be analyzed in conjunction with the distribution law of the shear stress of the anchor.

One part of anchor test [21-23] was selected as the example of steel bar antifloating anchor. The other parts of anchor tests $[17,18,23,24]$ were selected as the example of GFRP antifloating anchor. The calculation parameters and anchoring length of each test anchor are shown in Tables 1 and 2, and the distribution of shear stress along the anchoring depth is shown in Figures 5 and 6.

In Table 1, it can be known from the pull-out test of steel bar anchors in [23] that the anchoring length of steel bar anchors is much lower than the theoretical critical anchoring length. Combined with the distribution law of anchor shear stress shown in Figure 5(a), near the end of antifloating anchor, there is still a high shear stress between anchor body and anchoring solid, which then rapidly descends to 0 , and there is no excess anchoring length reserve. It is shown that the shorter anchoring length is not enough to provide enough contact area between anchor body and anchoring solid, and the bonding force between the two cannot be played normally. The drawing load can only be transferred to the surrounding rock and soil in a relatively shallow range, which leads to the shear stress of the interface between the anchor body and the anchoring solid far higher than the normal level, and eventually inevitably leads to the interface reaching the ultimate shear strength value prematurely, and the anchor body and the anchoring solid have relative slip, resulting in shear slip failure. The description of test anchor failure in [23] is consistent with the above analysis results, which can indirectly prove the rationality of the above critical anchoring length calculation method.

In Table 1, the pull-out test of the steel bar anchor in $[21,22]$ shows that the actual anchor anchoring length is longer than the theoretical critical anchoring length. Combined with the shear stress distribution of the anchor in Figures 5(b) and 5(c), it is shown that the antifloating anchor in the two tests has partial anchoring length reserve, the anchor body and anchoring solid can play their bonding role normally, and they have sufficient anchoring length for the downward transfer of drawing load. In addition, the actual anchoring length of the tested antifloating anchor in [22] is about $0.65 \mathrm{~m}$ longer than the theoretical critical anchoring length, accounting for $81 \%$ of the actual anchoring length. It shows that the test anchor is too long to be anchored, and a long part of the anchor does not play its role in the actual stress, which results in the waste of anchor material.

For GFRP bars, a similar conclusion can be obtained by combining Table 2 and Figure 6. When the anchoring length is lower than the theoretical critical anchoring length, there is no residual length reserve of the anchor under the action of drawing load, and the shear stress between the anchor and the anchoring solid is higher than the normal level, which leads to the shear-slip failure between the anchor and the anchoring solid. Similarly, anchors whose anchoring length is higher than the critical anchoring length have a partial length reserve, and the bonding force between the anchor body and the anchoring solid can play normally, with sufficient length for the downward transfer of the drawing load.

In addition, according to the comparison results of $[17,23]$ in Table 2, for GFRP antifloating anchors whose anchoring length is lower than the theoretical critical anchoring length, as the actual anchoring length is close to the critical anchoring length, the shear stress gradually tends to be normal, and the shear stress value near the end of the anchor gradually decreases.

The above results are summarized as follows: when the anchoring length is lower than the critical anchoring length, the shear stress between the anchor and the anchoring solid under the action of drawing load is higher than the normal level (the shear stress when the anchoring length is long enough), and the antifloating anchor thus suffers shear slip failure. As the actual anchoring length approaches the critical anchoring length, the shear stress becomes closer to the normal level. When the anchoring length is higher than the critical anchoring length, the anchor has some reserved length and enough length to transfer the load downward. However, the anchoring 


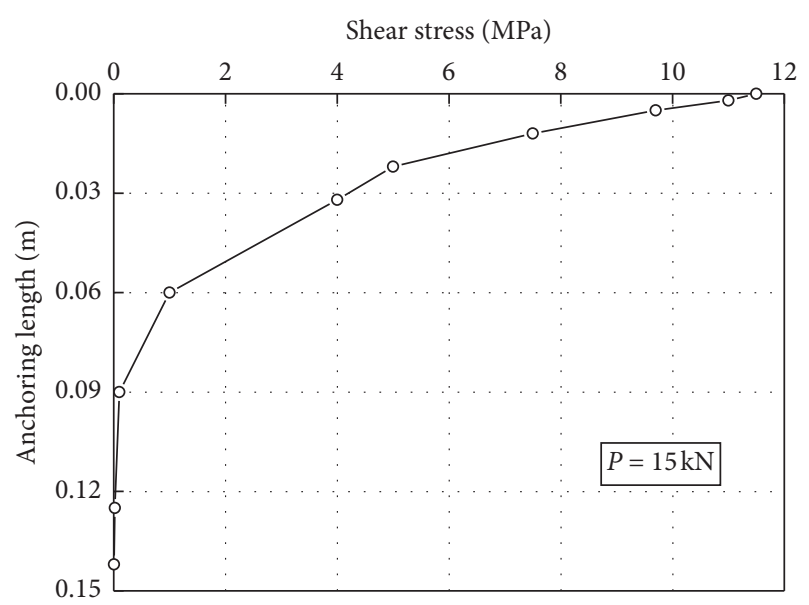

(a)

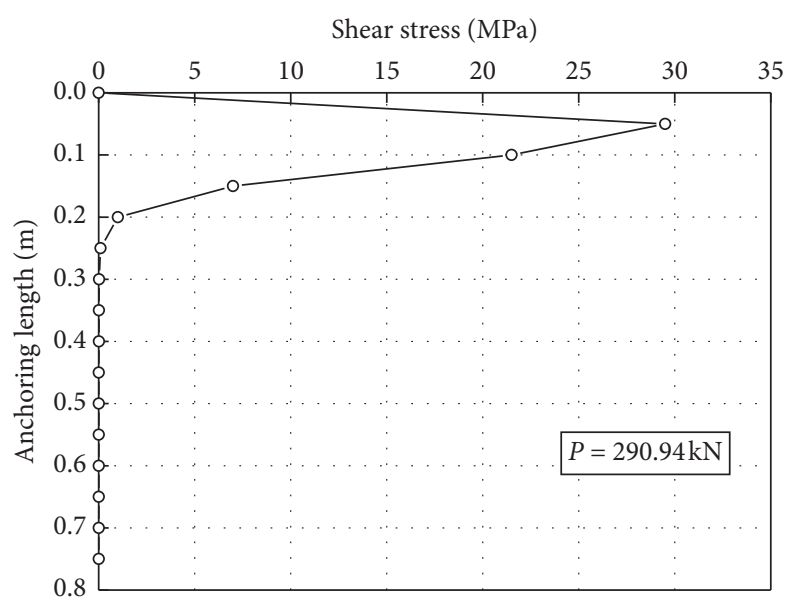

(b)

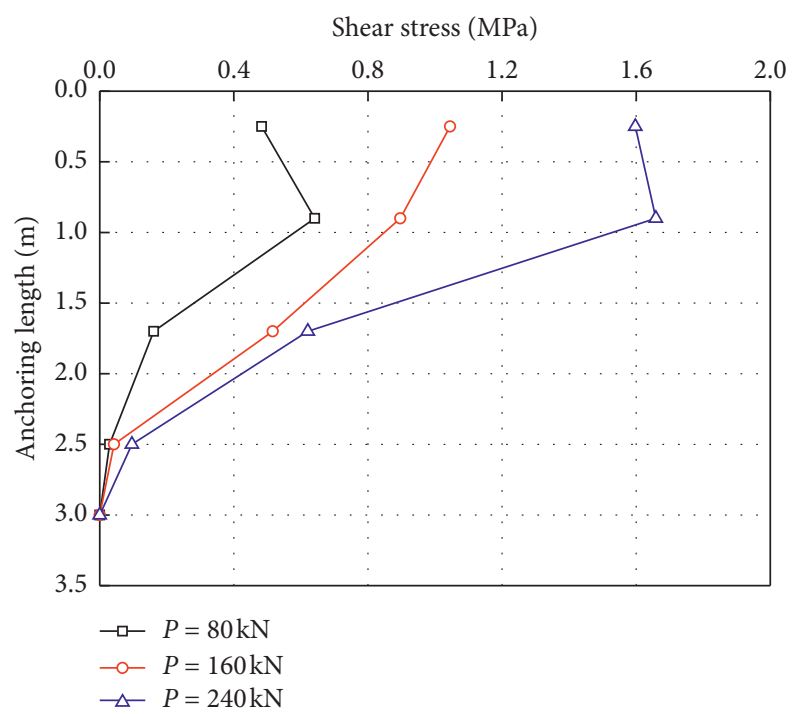

(c)

FIgURE 5: Distribution for the shear stress of steel anchors (a) [21]. (b) [22]. (c) [23].
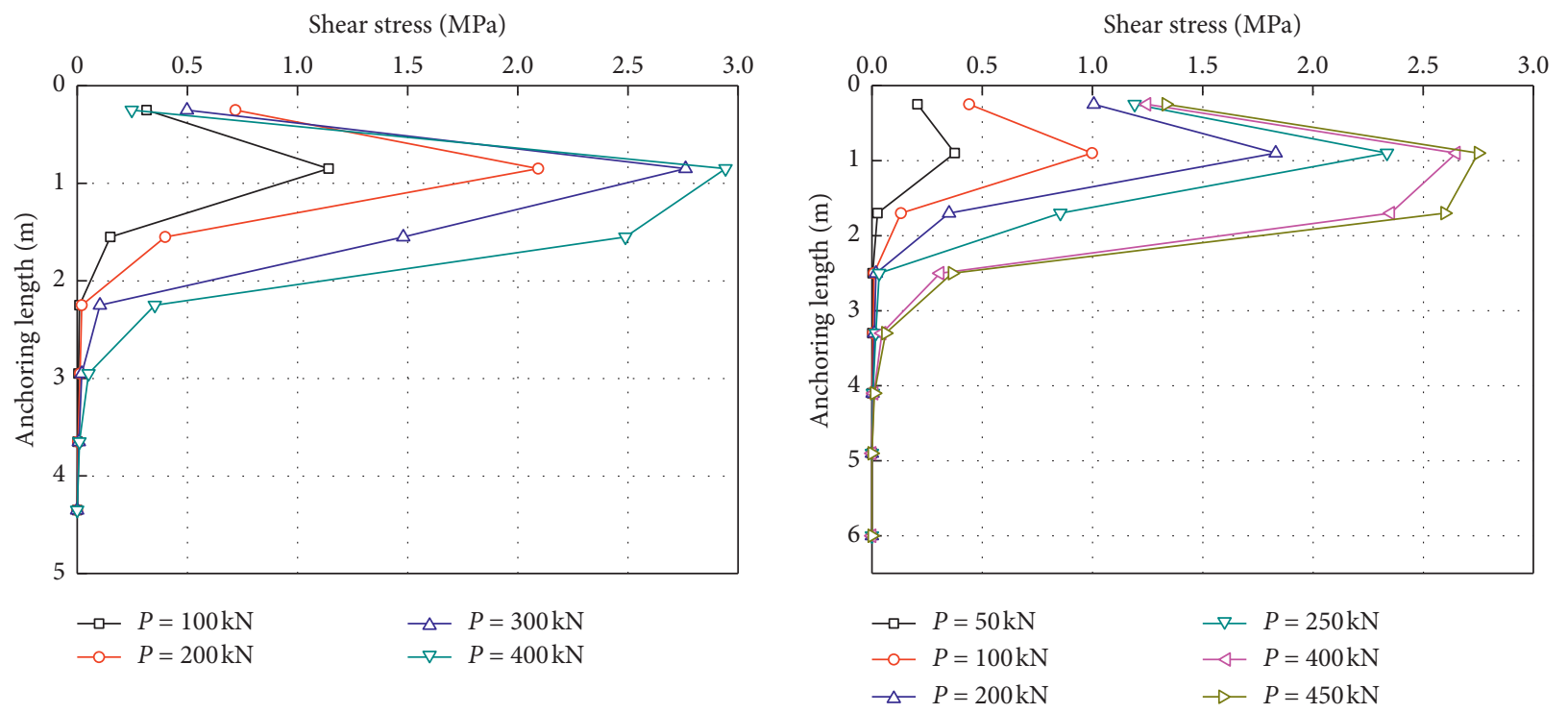

(a)

(b)

Figure 6: Continued. 


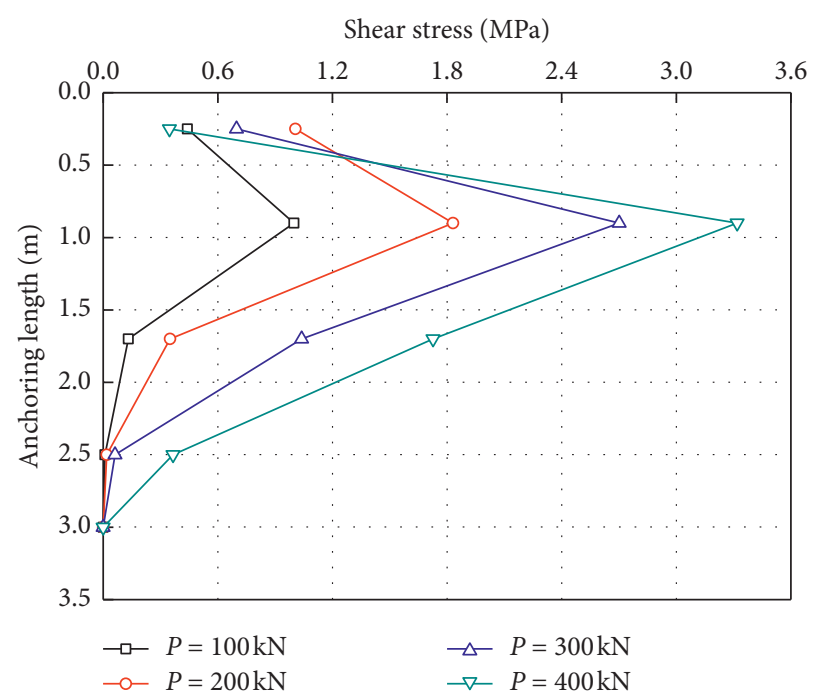

(c)

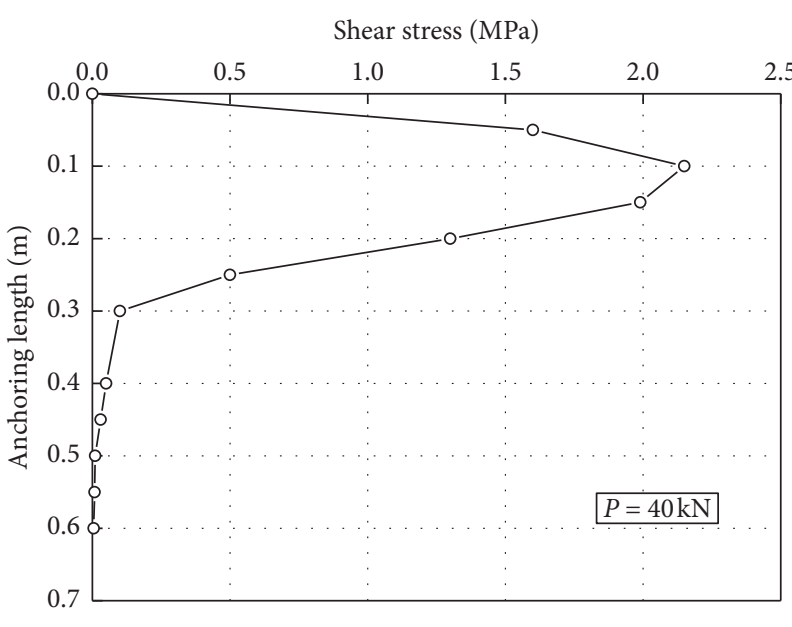

(d)

FIGURE 6: Distribution for the shear stress of GFRP anchors. (a) [17]. (b) [18]. (c) [23]. (d) [24].

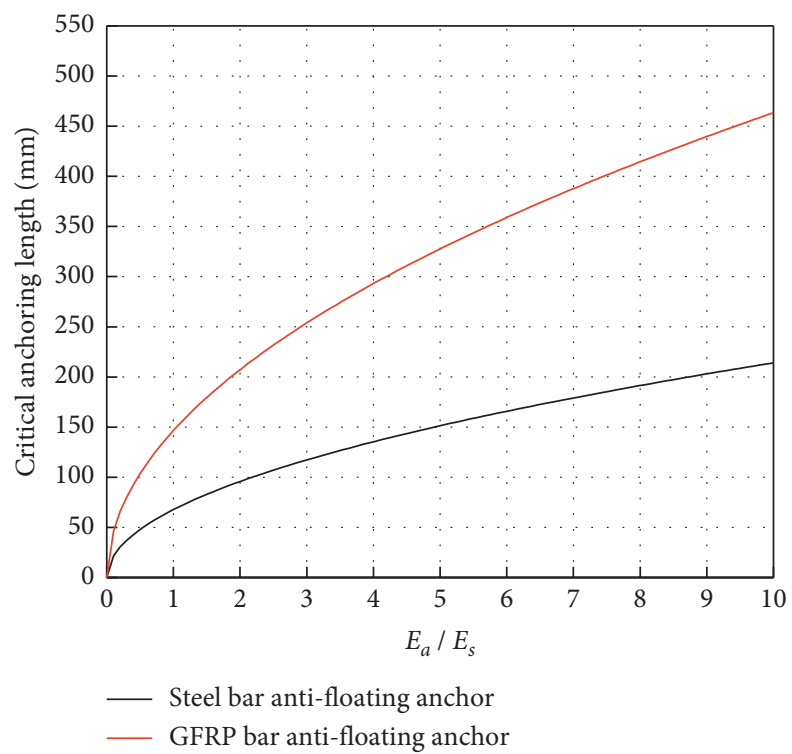

FIgURE 7: Influence of $E_{a} / E_{s}$ on critical anchoring length. $E_{a}$ is the elastic modulus of anchor.

length has little effect on improving the anchoring performance; instead, most of the anchor will not play its role, causing material waste.

\section{Influence of Elastic Modulus Ratio $(E a / E s)$ between Anchor and Rock Mass on Critical Anchorage Length}

It can be seen from equations (23) and (29) that the ratio of elastic modulus of anchor and rock mass has a great influence on the calculation of critical anchoring length, that is, the critical anchoring length of the same type of antifloating anchor in different environments is also different.
In practical application, the diameter of antifloating anchor is relatively large. Assuming that the anchor is located in the fourth system with a radius of $14 \mathrm{~mm}$ and its Poisson's ratio $\mu_{s}$ is usually 0.3 , the ratio relationship between the critical anchoring length and rock-soil mass elastic modulus of the anchor is shown in Figure 7:

As shown in Figure 7, $E_{a} / E_{s}$ of steel bar and GFRP bar are positively correlated with critical anchoring length. Under the same conditions of $E_{a} / E_{s}$, the critical anchoring length of GFRP bar is greater than that of steel bar. With the increase of $E_{a} / E_{s}$, the gap of critical anchoring length between them tends to increase.

The reasons for the above phenomenon can be summarized as follows: the elastic modulus of GFRP bar is much 
lower than that of steel bar (generally 4-5 times), and the deformation of GFRP bar is greater under the same load level. The test results show that the GFRP antifloating anchor body and anchoring solid have better coordinated deformation ability, the bond strength between the anchor body and the anchoring solid is lower, and slip failure is more likely to occur. In order to prevent the GFRP antifloating anchor from prematurely slipping and damaging the stability of the antifloating structure, it is necessary to lengthen the anchoring length and increase the adhesion force between the anchor and the anchoring solid (including chemical adhesive force, friction resistance, and mechanical bite force).

In addition, with the increase of $E_{a} / E_{s}$, that is, the strength of rock and soil gradually decreases, the ability of coordinated deformation between GFRP antifloating anchor and rock and soil further increases, and the increase amplitude is much greater than that of steel bar anchor, resulting in the decrease amplitude of bonding force between GFRP antifloating anchor and anchoring solid than that of steel bar anchor. Therefore, the increase amplitude of critical anchoring length of GFRP antifloating anchor is larger than that of steel bar antifloating anchor.

\section{Conclusion}

(1) Based on the ideal concentric thin-walled cylinder shear model and the simplified shear stress distribution model of antifloating anchor, the critical anchoring length of antifloating anchor with steel bar and GFRP bar is derived. By comparing the theoretical value of critical anchoring length with the measured value of an engineering example, and combining with the experimental results and phenomenon in an engineering example, the rationality of the analytical calculation method and the basic hypothesis are verified.

(2) With the critical anchoring length as the boundary, when the anchoring length is lower than the critical anchoring length, shear slip failure occurs between the anchor and the anchoring solid due to excessive shear stress under the action of drawing load. With the approach of the actual anchoring length and the critical anchoring length, the shear stress gradually decreases to the normal level. When the anchoring length is higher than the critical anchoring length, the anchor has some length reserve, and the load is transferred downward gradually because the anchor has enough anchoring length. To avoid waste, the anchoring length should not be too long.

(3) $E_{a} / E_{s}$ is positively correlated with the critical anchoring length. Under the same condition of $E_{a} / E_{s}$, the critical anchoring length of GFRP antifloating anchor is greater than that of steel bar antifloating anchor. With the increase of $E_{a} / E_{s}$, the difference of critical anchoring length between them increases gradually.

\section{Data Availability}

The experimental data used to support the findings of this study will be made available upon request.

\section{Conflicts of Interest}

The authors declare that there are no conflicts of interest regarding the publication of this paper.

\section{Acknowledgments}

This work was supported by the National Natural Science Foundation of China (51708316 and 51778312), the China Postdoctoral Science Foundation Funding (2018M632641); the Shandong Provincial Postdoctoral Innovation Program of China (201903043); Higher Educational Science and Technology Program of Shandong Province (J16LG02); Qingdao Postdoctoral Applied Research Program (2018101); and Key Program of Natural Science Foundation of Shandong Province (ZR2020KE009).

\section{References}

[1] Z. Achillides and K. Pilakoutas, "Bond behavior of fiber reinforced polymer bars under direct pullout conditions," Journal of Composites for Construction, vol. 8, no. 2, pp. 173-181, 2004.

[2] X. Bai, X. Liu, M. Zhang et al., "Stress transfer properties and displacement difference of GFRP antifloating anchor," $A d$ vances in Civil Engineering, vol. 2020, p. 18, Article ID 8894720, 2020.

[3] H. Ashrafi, M. Bazli, A. Vatani Oskouei et al., "Effect of sequential exposure to UV radiation and water vapor condensation and extreme temperatures on the mechanical properties of GFRP bars," Journal of Composites for Construction, vol. 22, no. 1, Article ID 04017047, 2017.

[4] P. V. Vijay and H. V. S. Gangarao, "Bending behavior and deformability of glass fiber-reinforced polymer reinforced concrete members," ACI Structural Journal, vol. 98, no. 6, pp. 834-842, 2011.

[5] V. M. Karbhari, J. W. Chin, D. Hunston et al., "Durability gap analysis for fiber-reinforced polymer composites in civil infrastructure," Journal of Composites for Construction, vol. 7, no. 3, pp. 238-247, 2003.

[6] D.-S. Xu and J.-H. Yin, "Analysis of excavation induced stress distributions of GFRP anchors in a soil slope using distributed fiber optic sensors," Engineering Geology, vol. 213, pp. 55-63, 2016.

[7] Z. Kuang, M.-Y. Zhang, and X.-Y. Bai, "Load-bearing characteristics of fibreglass uplift anchors in weathered rock," Proceedings of the Institution of Civil Engineers-Geotechnical Engineering, vol. 173, no. 1, pp. 49-57, 2020.

[8] C.-C. Zhang, H.-H. Zhu, Q. Xu, B. Shi, and G.-X. Mei, "Timedependent pullout behavior of glass fiber reinforced polymer (GFRP) soil nail in sand," Canadian Geotechnical Journal, vol. 52, no. 6, pp. 671-681, 2015.

[9] D. Trejo, P. Gardoni, and J. J. Kim, "Long-Term performance of glass fiber-reinforced polymer reinforcement embedded in concrete," ACI Materials Journal, vol. 108, no. 6, pp. 605-613, 2011.

[10] X. Y. Bai, M. Y. Zhang, L. Zhu et al., "Experimental study on shear characteristics of interface of full-bonding glass fiber 
reinforced polymer anti-floating anchors," Chinese Journal of Rock Mechanics and Engineering, vol. 37, no. 6, pp. 1407-1418, 2018.

[11] R. W. Cooke and G. Price, Strains and Displacements Around Friction Piles, Building Research Station, London, UK, 1978.

[12] M. F. Randolph and C. P. Wroth, "Analysis of deformation of vertically loaded piles," Journal of Geotechnical and Geoenvironmental Engineering, vol. 104, no. 12, pp. 465-488, 1978.

[13] R. W. Cooke, G. Price, and K. Tarr, "Jacked piles in London clay: a study of load transfer and settlement under working conditions," Géotechnique, vol. 29, no. 2, pp. 113-147, 1979.

[14] Y.-S. Kim, H.-J. Sung, H.-W. Kim, and J.-M. Kim, "Monitoring of tension force and load transfer of ground anchor by using optical FBG sensors embedded tendon," Smart Structures and Systems, vol. 7, no. 4, pp. 303-317, 2011.

[15] J.-P. Won, C.-G. Park, H.-H. Kim, S.-W. Lee, and C.-I. Jang, "Effect of fibers on the bonds between FRP reinforcing bars and high-strength concrete," Composites Part B: Engineering, vol. 39, no. 5, pp. 747-755, 2008.

[16] N.-K. Kim, "Performance of tension and compression anchors in weathered soil," Journal of Geotechnical and Geoenvironmental Engineering, vol. 129, no. 12, pp. 1138-1150, 2003.

[17] X. Y. Bai, M. Y. Zhang, and H. L. Kou, "Field experimental study of load transfer mechanism of GFRP anti-floating anchors based on embedded bare fiber bragg grating sensing technology," Engineering Mechanics, vol. 32, no. 8, pp. 172181, 2015.

[18] H.-L. Kou, W. Guo, and M.-Y. Zhang, "Pullout performance of GFRP anti-floating anchor in weathered soil," Tunnelling and Underground Space Technology, vol. 49, pp. 408-416, 2015.

[19] G. B. Maranan, A. C. Manalo, W. Karunasena, and B. Benmokrane, "Pullout behaviour of GFRP bars with anchor head in geopolymer concrete," Composite Structures, vol. 132, pp. 1113-1121, 2015.

[20] C. A. You, "Mechanical analysis of fully-grouted anchor," Chinese Journal of Rock Mechanics and Engineering, vol. 19, no. 3, pp. 339-341, 2000.

[21] S. C. Gu and X. P. Cui, "Characteristic research on the anchorage load transfer of anchor in concrete," Concrete, vol. 32, no. 10 , pp. 27-30, 2010.

[22] Y. Z. Zhang, Z. H. Shi, and J. Zhang, "Experimental study of load distribution of anchoring section for rock anchors," Rock \& Soil Mechanics, vol. 32, no. 2, pp. 184-188, 2010.

[23] X. Y. Bai, M. Y. Zhang, and N. Yan, "Field contrast test and mechanism analysis on anchorage performance of antifloating anchors with two different materials," China Civil Engineering Journal, vol. 48, no. 8, pp. 38-46, 2015.

[24] Y. C. Kuang, Y. Xu, and L. W. Ou, "Research on the bond behavior of a glass-fiber-reinforced plastic anchor," Journal of Harbin Engineering University, vol. 37, no. 12, pp. 1658-1664, 2016. 